\title{
Integrasi Modern Honey Network Dengan Grafana Untuk Visualisasi
}

\author{
Novandha Yudyanto', Syaifuddin², Yufis Azhar ${ }^{3}$ \\ 1,2,3 Jurusan Teknik Informatika, Universitas Muhammadiyah Malang \\ e-mail: no.panda94@gmail.com ${ }^{* 1}$, saifuddin@umm.ac.id ${ }^{2}$, yufis@umm.ac.id ${ }^{3}$
}

\begin{abstract}
Abstrak
Internet merupakan komoditas utama dalam hal komunikasi pada saat ini. Namun seiring dengan perkembangan zaman, penyerangan dalam internet semakin bertambah. Demi mencegah serangan tersebut banyak sistem atau program yang telah dikembangakan salah satunya ialah Honeypot . Honeypot mampu menahan, mendeteksi, dan mencatat serangan yang diterima guna mencari informasi mengenai serangan tersebut. Dengan menggunakan informasi tersebut akan lebih mudah untuk mencegah kerusakan apabila terjadi serangan yang serupa. Akan tetapi Honeypot masih belum banyak diminati oleh komunitas keamanan jaringan dikarenakan oleh rumitnya pengelolaan dan pemeliharaannya. Modern Honey Network atau MHN merupakan program open-source yang mampu menjalankan beberapa Honeypot sekaligus mengumpulkan log serangan yang diterima Honeypot tersebut. MHN bertujuan untuk mengatasi masalah rumitnya pengelolaan dan pemeliharaan Honeypot . Namun MHN tidak memiliki visualisasi untuk menganalisis pola serangan yang diterima oleh Honeypot. Hal ini tentu menyulitkan pengguna terlebih dengan banyaknya log yang dapat dihasilkan oleh Honeypot . Karena itulah dibutuhkan program untuk visualisasi log tersebut. Dalam penelitian ini Grafana digunakan untuk visualisasi log pada MHN. Dengan mengintegrasikan Grafana dengan MHN diharapkan pengguna MHN tidak kesulitan dalam membaca dan menganalisa log Honeypot .
\end{abstract}

Kata Kunci: Honeypot, Modern Honey Network, Visualisasi, Grafana

\begin{abstract}
The internet is the main commodity in terms of communication at the moment. But along with the times, attacks on the internet are increasing. In order to prevent these attacks many systems or programs have been developed, one of which is Honeypot . Honeypot can resist, detect, and record attacks received to find information about these attacks. Using those information will be easier to prevent damage in case of a similar attack. However, Honeypot is still not much in term of usage by the network security community due to the complexity of its management and maintenance. Modern Honey Network or MHN is an open-source program that is capable of running multiple Honeypot $s$ while simultaneously gathering logs of attacks received by the Honeypot. MHN aims to overcome the complex problem of managing and maintaining of a Honeypot . However, MHN does not have a visualization to analyze the attack patterns received by the Honeypot. This becomes a difficulty for users especially with the number of logs that can be generated by Honeypot. That's why a program is needed for the log visualization. In this study Grafana is used for log visualization. By integrating Grafana with MHN, it is expected that MHN users will have no difficulty in reading and analyzing the log from Honeypot .
\end{abstract}

Keywords: Honeypot, Modern Honey Network, Visualization, Grafana

\section{Pendahuluan}

Pada saat ini kebutuhan akan komunikasi sangat tinggi. Tidak hanya komunikasi dekat tetapi komunikasi jarak jauh bahkan mencapai global. Dengan internet kita mampu untuk berkomunikasi tidak hanya satu kota, pulau, atau Negara, akan tetapi kita mampu berkomunikasi dengan orang lain di balik bumi ini. Perkembangan internet sangat cepat, bahkan pada tahun 2014 sudah ada lebih dari 1 milyar domain yang ada di internet[1] dan pada tahun yang sama terdapat 3 milyar pengguna internet[2]. Internet menjadi alat komunikasi yang inovatif dalam sejarah manusia bahkan menjadi inovasi yang paling penting yang pernah dikembangkan oleh manusia. 
Akan tetapi, terdapat sebagian orang yang memanfaatkan internet untuk kepentingan mereka sendiri yang menyebabkan orang lain mengalami kerugian. Mereka menyerang komputer dengan berbagai cara seperti malware, scanning, brute force, DDoS yang menyebabkan kerugian terhadap yang diserang. Meski begitu sebagian orang yang menerima serangan tersebut tidak mengetahui adanya serangan. Mereka biasanya kekurangan informasi mengenai dari mana serangan itu berasal, siapa yang menyerang, bagaimana cara menyerang, dan kapan serangan tersebut dilakukan. Karena itulah dibutuhkan sebuah alat atau sistem bantu untuk mendeteksi serangan yang mereka terima, salah satunya ialah honeypot

Honeypot merupakan sebuah alat keamanan jaringan dengan tujuan untuk diserang oleh peretas[3][4]. Honeypot mempunyai tujuan untuk mengumpulkan semua informasi mengenai peretas yang nantinya dianalisa dan membuat penanggulangan terhadap serangan serupa[5]. Honeypot berbeda dari alat keamanan jaringan yang lain seperti Firewall atau Intrusion Detection Systems (IDS) karena honeypot tidak hanya mampu menyelesaikan sebuah masalah namun bisa menyelesaikan beberapa masalah sekaligus. Contohnya adalah honeypot bisa menghalangi sebuah serangan jaringan layaknya sebuah Firewall dan honeypot mampu mendeteksi sebuah serangan layaknya IDS pada saat yang bersamaan[6]. Akan tetapi honeypot masih kurang digunakan oleh organisasi ataupun perusahaan karena mereka beranggapan honeypot sulit untuk penerapan, konfigurasi maupun pemeliharaannya.

Pada tahun 2014 Threatstream (sekarang Anomali) mengembangkan sebuah sistem terpusat yang mempunyai sekumpulan sensor honeypot yaitu Modern Honey Network atau MHN. Modern Honey Network merupakan sebuah sistem manajemen yang mampu menjalankan banyak sensor dalam satu waktu yang singkat[7]. Selain itu di dalam sistem tersebut terdapat web interface yang berfungsi untuk men-deploy honeypot, dan melihat log penyerangan. Tetapi pengguna kesulitan untuk membaca pola penyerangan dikarenakan data yang dihasilkan hanya berupa log tanpa visualisasi seperti diagram batang atau diagram garis yang mepresentasikan pola serangan tersebut. Terlebih log yang ditampilkan oleh MHN hanya 10 log per halaman, dibandingkan dengan ribuan log yang dapat dihasilkan dari honeypot, hal ini tentu menyulitkan pengguna.. maka dari itu dibutuhkan sebuah perangkat lunak yang dapat memvisualisasikan untuk mempermudah melihat statistik dan juga mempermudah dalam menganalisa log yang dihasilkan sensor honeypot. Dalam penelitian ini hasil dari penyerangan akan divisualisasikan dengan menggunakan Grafana.

Grafana merupakan perangkat lunak open source yang mempunyai fungsi untuk memvisualisasikan, memberi peringatan, dan men-query data[8]. Dengan mengintegrasikan Modern Honey Network dengan Grafana, pembacaan log yang telah direkam oleh sensor Honeypot dapat divisualisasikan.

Berdasarkan penelitian sebelumnya yang dilakukan oleh Hibatul Wafi dkk. dengan judul "Implementation of a Modern Security Systems Honeypot Honey Network on Wireless Network" membahas bagaimana menerapkan sistem Modern Honey Network pada jaringan wireless dengan menggunakan beberapa Honeypot[7], sedangkan peneliti akan menerapkan Modern Honey Network dan akan diintegrasikan dengan Grafana untuk memvisualisasikan log yang didapat dari Honeypot. Sedangkan pada penelitian yang dilakukan oleh Vesselin Bontchev dan Veneta Yosifosa pada penelitian "Analysis of the Global Attack Landscape Using Data from a Telnet Honeypot"[9], membahas bagaimana menggabungkan Grafana dengan sebuah Honeypot, tetapi peneliti menggabungkan Grafana dengan beberapa Honeypot melalui Modern Honey Network.

Berdasarkan latar belakang diatas, peneliti bertujuan untuk mengimplementasikan Modern Honey Network dan mengintegrasikannya dengan Grafana.yang nantinya peneliti berharap bisa memudahkan seorang administrator dalam menganalisa log yang dihasilkan oleh Modern Honey Network.

\section{Metode Penelitian}

Pada penelitian ini peneliti menggunakan model proses penelitian sekuensial linier. Berikut adalah gambaran bagaimana alur sekuensial linier menurut Pressman[10]: 


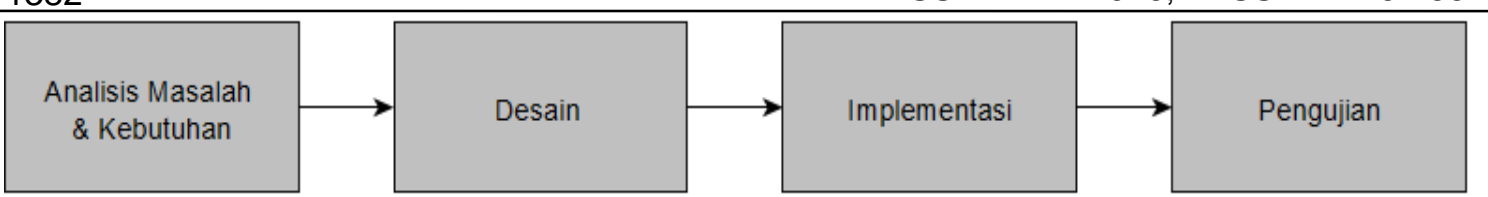

Gambar 1 Model Proses Sekuensial Linier

Analisis masalah merupakan langkah awal agar peneliti mengerti akan masalah yang akan dihadapi. Masalah yang dihadapi pada penelitian ini ialah banyak pengguna kurang memahami akan serangan yang diterima seperti darimana serangan itu datang, serangan apa yang dilakukan, kapan penyerangan itu terjadi. Honeypot menjadi salah satu solusi untuk masalah tersebut tetapi honeypot tersebut jarang digunakan karena sulit untuk penerapan, konfigurasi ataupun pemeliharaannya. Modern Honey Network atau MHN menjadi salah satu cara supaya pengguna mampu menggunakan honeypot - honeypot tersebut. Tetapi MHN kurang dalam hal mempresentasikan statistik serangan. MHN hanya menampilkan log - log serangan dalam bentuk daftar dan dalam satu halaman ditampilkan hanya 10 daftar saja, padahal log - log yang diterima oleh MHN mampu mencapai ribuan. hal ini tentu saja merepotkan pengguna MHN yang ingin menganalisa serangan tersebut.

Setelah analisis masalah selesai dilanjutkan dengan analisis kebutuhan untuk menganalisis kebutuhan apa saja yang diperlukan pada penelitian ini. Berikut adalah tabel kebutuhan yang dibutuhkan pada penelitian ini, Tabel 1 berisi kebutuhan perangkat keras, Tabel 2 perangkat lunak untuk MHN Honeypot serta Tabel 3 berisi kebutuhan perangkat lunak untuk penyerang.

Tabel 4 Kebutuhan Perangkat Keras

\begin{tabular}{|l|l|l|l|l|l|}
\hline & Laptop 1 & Laptop 2 & Laptop 3 & Komputer 1 & Komputer 2 \\
\hline $\begin{array}{l}\text { Sistem } \\
\text { Operasi }\end{array}$ & $\begin{array}{l}\text { Ubuntu 18.04 } \\
\text { Server }\end{array}$ & $\begin{array}{l}\text { Ubuntu 18.04 } \\
\text { Desktop }\end{array}$ & $\begin{array}{l}\text { Ubuntu 18.04 } \\
\text { Desktop }\end{array}$ & $\begin{array}{l}\text { Kali Linux } \\
2020.1 \mathrm{~b}\end{array}$ & Windows 7 \\
\hline $\begin{array}{l}\text { Processo } \\
\text { r }\end{array}$ & AMD 2 Core & Inter 4 Core & Intel 2 Core & Intel 4 Core & Intel 4 Core \\
\hline RAM & $4 \mathrm{~GB}$ & $4 \mathrm{~GB}$ & $2 \mathrm{~GB}$ & $8 \mathrm{~GB}$ & $8 \mathrm{~GB}$ \\
\hline Storage & $30 \mathrm{~GB}$ & $30 \mathrm{~GB}$ & $20 \mathrm{~GB}$ & $30 \mathrm{~GB}$ & $120 \mathrm{~GB}$ \\
\hline IP & $\begin{array}{l}192.168 .1 .20 / 2 \\
4\end{array}$ & $\begin{array}{l}192.168 .1 .21 / 2 \\
4\end{array}$ & $\begin{array}{l}192.168 .1 .22 / 2 \\
4\end{array}$ & $\begin{array}{l}192.168 .1 .35 / 2 \\
4\end{array}$ & $\begin{array}{l}192.168 .1 .30 / 2 \\
4\end{array}$ \\
\hline Peran & $\begin{array}{l}\text { Server MHN } \\
\text { dan Grafana }\end{array}$ & $\begin{array}{l}\text { Honeypot } \\
\text { Dionaea }\end{array}$ & $\begin{array}{l}\text { Honeypot } \\
\text { Cowrie }\end{array}$ & Penyerang & Akses Grafana \\
\hline
\end{tabular}

Tabel 5 Kebutuhan Perangkat Lunak sisi MHN

\begin{tabular}{|c|l|c|}
\hline Nama & Deskripsi & Versi \\
\hline $\begin{array}{c}\text { Modern Honey } \\
\text { Getwork }\end{array}$ & $\begin{array}{l}\text { Perangkat Lunak yang berperan sebagai pusat untuk } \\
\text { mengumpulkan data dari honeypot }\end{array}$ & 6.7 \\
\hline MySQL & $\begin{array}{l}\text { Perangkat lunak untuk visualisasi data yang } \\
\text { didapatkan dari database }\end{array}$ & $\begin{array}{l}\text { Database open source berbasis Structured Query } \\
\text { Language yang digunakan untuk menyimpan data dari } \\
\text { database MHN }\end{array}$ \\
\hline Python & $\begin{array}{l}\text { Bahasa Pemrograman untuk menjalankan program } \\
\text { berbasis python }\end{array}$ & 3.8 .3 \\
\hline Cron & $\begin{array}{l}\text { Perangkat Lunak untuk menjalankan perintah } \\
\text { berdasarkan jeda waktu yang telah ditentukan }\end{array}$ & \\
\hline Dionaea & $\begin{array}{l}\text { Honeypot untuk menangkap exploitasi dengan cara } \\
\text { membuka layanan yang kerap menjadi sasaran }\end{array}$ & 0.8 .0 \\
\hline Cowrie/Kippo & $\begin{array}{l}\text { Honeypot untuk menangkap serangan brute force dan } \\
\text { kegiatan penyerang pada layanan SSH dan Telnet }\end{array}$ & 2.1 .0 \\
\hline
\end{tabular}




\begin{tabular}{|c|l|l|}
\hline \multicolumn{2}{|l}{ Tabel 6 Kebutuhan Perangkat Lunak Penyerang } \\
\hline Nama & Deskripsi & Versi \\
\hline Hping3 & $\begin{array}{l}\text { Perangkat lunak bertujuan untuk mencari informasi } \\
\text { tentang target mulai dari IP target dalam jaringan } \\
\text { sampai layanan yang terbuka pada target }\end{array}$ & 7.80 \\
\hline Metasploit & $\begin{array}{l}\text { Perangkat lunak yang mampu memanipulasi paket } \\
\text { yang dikirimkan seperti besar dan jumlah }\end{array}$ & 6.7 \\
\hline & $\begin{array}{l}\text { Perangkat lunak bertujuan untuk penetration testing } \\
\text { atau uji coba penetrasi pada kelemahan yang dimiliki } \\
\text { suatu layanan }\end{array}$ & 8.0 .20 \\
\hline
\end{tabular}

Tahap berikutnya ialah desain. Pada tahap ini akan dibahas bagaimana secara garis besar cara kerja dari sistem yang akan dibangun. Ada dua hal yang akan dibahas yang pertama adalah topologi sistem dan yang kedua adalah alur data log.

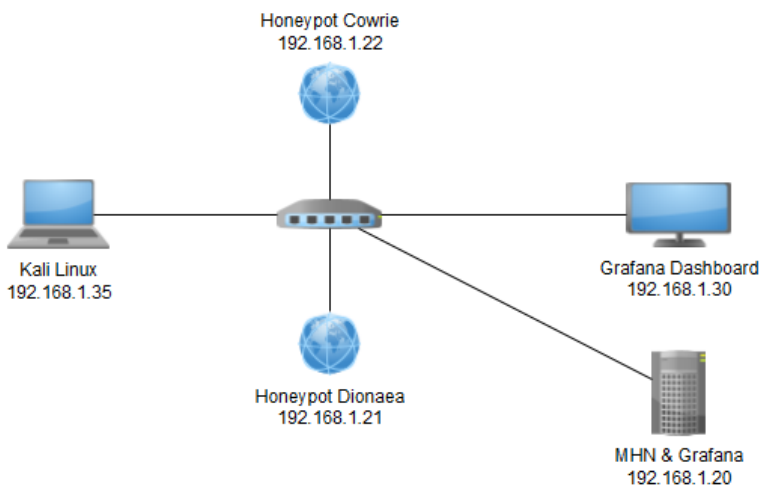

Gambar 2 Desain Arsitektur Sistem

Pada Gambar 3 terlihat ada empat unsur penting yaitu komputer penyerang, honeypot cowrie dan dionaea, server MHN yang terintegrasi dengan Grafana, dan sebuah PC untuk melihat hasil visualisasi dari Grafana . Komputer penyerang akan dipasang sistem operasi Kali karena dalam sistem operasi tersebut sudah terpasang perangkat lunak untuk menyerang honeypot. Honeypot dionaea dan cowrie terpasang pada laptop terpisah agar mudah untuk melihat hasil serangan dari dua honeypot tersebut. Serangan yang diterima oleh honeypot akan direkam dan dikirimkan ke MHN. MHN akan menerima dan menampung data dari honeypot kedalam database MHN yaitu MongoDB dan dapat dilihat pada Web Apps milik MHN. Data tersebut kemudian akan dikirikan menuju Grafana , akan tetapi Grafana tidak mendukung penggunaan MongoDB sebagai sumber data. Karena itu dibutuhkan database yang didukung oleh Grafana, disini peneliti memilih database MySQL.

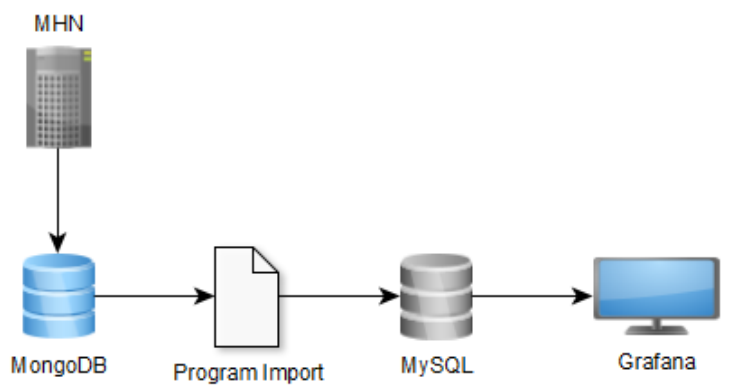

Gambar 3 Alur Data log Honeypot

Untuk mengirimkan data dari MongoDB menuju MySQL peneliti membuat sebuah program yang mampu membaca record dari MongoDB, kemudian mengirimkannya menuju MySQL dan akan memperbarui atau update record tersebut jika record tersebut sudah ada. Record pada MySQL akan dibaca oleh Grafana untuk divisualisasikan pada panel - panel di 
dalam suatu dashboard. PC dapat melihat hasil visualisasi dari dashboard tersebut menggunakan web browser.

Setelah desain selesai dibuat maka dilakukanlah tahap implementasi. Peneliti akan mengimplementasi sesuai dengan desain yang dibuat pada tahap sebelumnya. Dimulai dari menyiapkan perangkat keras dan perangkat lunak yang dibutuhkan, sampai memasang aplikasi yang dibutuhkan. Terakhir adalah tahap pengujian. Tahap ini merupakan tahapan dimana sistem yang telah didesain dan diimplementasi diuji untuk melihat apakah sistem sudah sesuai dengan harapan pada penelitian ini. Proses pengujian terlihat pada Gambar 4

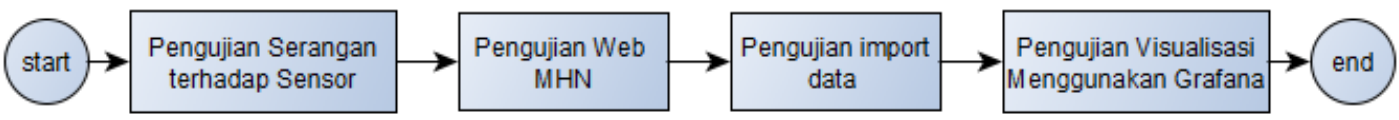

Gambar 4 Alur Pengujian

Pengujian dimulai dari serangan terhadap sensor. Penyerangan pertama ialah port scanning, kemudian dilanjutkan dengan Denial of Service dengan cara pengiriman paket secara terus menerus dan terakhir adalah exploitasi port yang terbuka. Pengujian selanjutnya adalah memeriksa apakah server MHN menerima log dari sensor. Pengujian dilakukan dengan menggunakan Web Apps yang dimiliki MHN. Setelah log berhasil ditampilkan pada Web App pengujian selanjutnya adalah mengimpor log tersebut menuju database MySQL karena database MHN, MongoDB tidak disupport oleh Grafana . Disini peneliti membuat program sendiri dengan cara kerja program pertama akan mengambil record dari MongoDB terlebih dahulu kemudian disimpan pada suatu object. Setelah itu program akan memasukkan record pada object menuju MySQL dan akan meng-update jika pada tabel telah terisi record dari record MongoDB yang lama. Terakhir adalah visualisasi pada Grafana . Panel pada Grafana akan memvisualisasikan data dengan menggunakan query yang sebelumnya telah diatur sedemikian rupa agar dapat memilih data apa saja yang akan ditampilkan pada panel. Panel tersebut akan ditempatkan pada dashboard bersama dengan panel lain yang menampilkan data berbeda.

\section{Hasil Penelitian dan Pembahasan}

\subsection{Hasil Pengujian Serangan}

Dalam pengujian serangan terhadap Honeypot, ada tiga jenis serangan yang dilakukan, Port Scanning, Port Exploit, Denial of Service

a) Port Scanning

Uji coba Scanning dilakukan dengan menggunakan program Nmap yang terpasang pada sistem operasi Kali. target pertama dari Scanning ialah Honeypot Dionaea pada IP 192.168.1.21 dengan perintah "Nmap -sS -p 1-1000 -sC 192.168.1.21", dan pada Gambar 6 adalah hasilnya

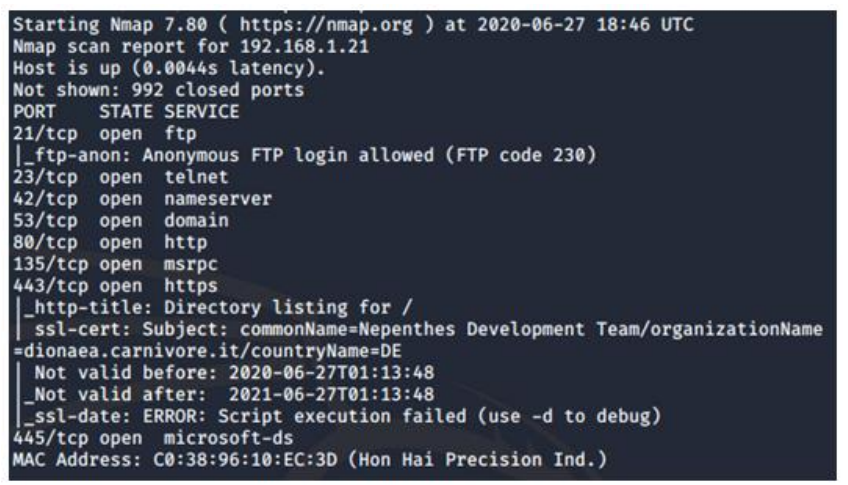

Gambar 6 Hasil dari Port Scanning pada Dionaea

Target kedua ialah Honeypot Cowrie. Perintah untuk Port Scanning adalah "Nmap-sS p 1-1000 -O -sC 192.168.1.22" dan berikut Gambar 7 adalah hasilnya

REPOSITOR, Vol. 2, No. 10, Oktober 2020, Pp. 1380-1389 
b) Exploit Port

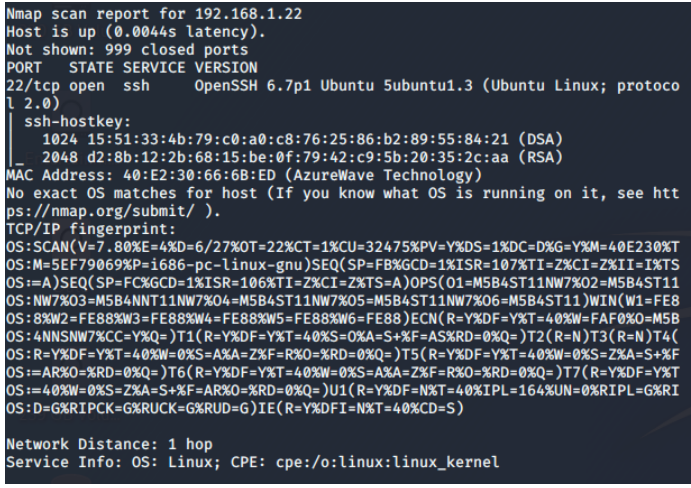

Gambar 7 Hasil dari Port Scanning pada Cowrie

Pengujian berikutnya ialah eksploitasi kepada Port dengan menggunakan program metasploit. Target pertama ialah Honeypot Dionaea pada Port 445 dimana Port tersebut sering menjadi target untuk eksploitasi. Exploit yang digunakan ialah ms08_067_netapi, dan berikut adalah hasilnya

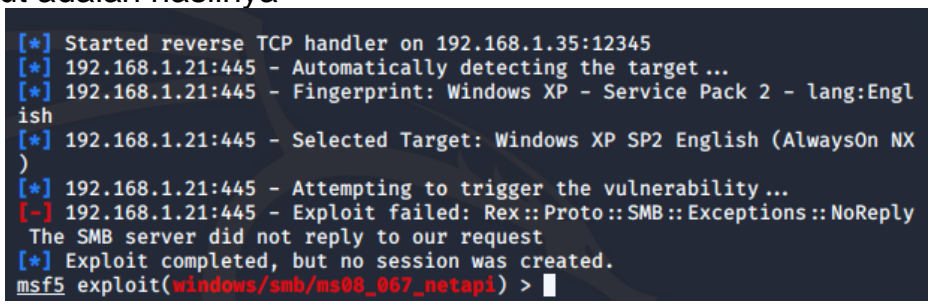

Gambar 8 Hasil exploitasi Port 445 pada DIonaea

Berikutnya eksploitasi terhadap Honeypot Cowrie pada Port 22. Exploit yang digunakan ialah sshexec dengan hasil berikut

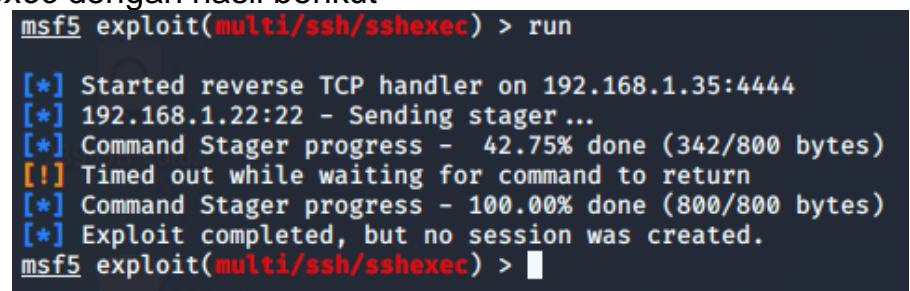

c) Denial of Service (DoS)

Gambar 9 Hasil Exploitasi pada Cowrie

Pengujian terakhir ialah Denial of Service dengan menggunakan program Hping3. Target yang diserang pertama ialah Dionaea pada Port 80. Perintah yang digunakan ialah " Hping3 -flood -p 80 -S 192.168.1.21" dan berikut adalah prosesnya

HPING 192.168.1.21 (eth0 192.168.1.21): S set, 40 headers $+\theta$ data bytes hping in flood mode, no replies will be shown

Gambar 10 Proses Denial of Service pada Dionaea

Dilanjutkan dengan serangan terhadap Cowrie dengan perintah yang sama yakni "Hping3 -flood -p 22 -S 192.168.1.22" dan berikut merupakan prosesnya

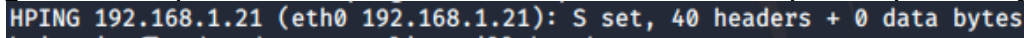

\subsection{Hasil Pengujian Serangan}

Gambar 11 Proses Denial of Service pada Cowrie

MHN akan menerima log serangan yang diterima Honeypot . Dari serangan dari sub bab pengujian, Dionaea menangkap banyak serangan terutama dari serangan berupa scanning yang dilakukan program Nmap. Dionaea juga menangkap serangan exploit yang dikirimkan oleh metasploit pada Port 445 dan serangan DoS yang dikirimkan pada Port 80 seperti yang terlihat pada Gambar 12 dan Gambar 13: 


\begin{tabular}{|c|c|c|c|c|c|c|c|}
\hline & Date & Sensor & Country & Src IP & Dst port & Protocol & Honeypot \\
\hline 1 & $2020-06-2802: 16: 58$ & dionaea & 0 & 192.168.1.35 & 445 & smbd & dionaea \\
\hline 2 & $2020-06-2802: 13: 53$ & dionaea & 2 & 192.168.1.35 & 8085 & pсap & dionaea \\
\hline 3 & $2020-06-28$ 02:13:53 & dionaea & 7 & 192.168.1.35 & 1300 & pcap & dionaea \\
\hline 4 & $2020-06-28$ 02:13:53 & dionaea & 7 & 192.168.1.35 & 4242 & pcap & dionaea \\
\hline 5 & $2020-06-2802: 13: 53$ & dionaea & 7 & 192.168.1.35 & 1042 & pcap & dionaea \\
\hline 6 & $2020-06-2802: 13: 53$ & dionaea & 8 & 192.168.1.35 & 90 & pcap & dionaea \\
\hline 7 & $2020-06-2802: 13: 53$ & dionaea & 7 & 192.168 .1 .35 & 1055 & pсар & dionaea \\
\hline 8 & $2020-06-2802: 13: 53$ & dionaea & 8 & 192.168.1.35 & 57797 & pсар & dionaea \\
\hline 9 & $2020-06-28$ 02:13:53 & dionaea & $?$ & 192.168.1.35 & 1914 & pcap & dionaea \\
\hline 10 & $2020-06-28$ 02:-13:53 & dionaea & 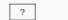 & 192.168.1.35 & 3690 & pcap & dionaea \\
\hline
\end{tabular}

Gambar 12 Serangan Nmap dan Metaslpoit pada Dionaea

\begin{tabular}{|c|c|c|c|c|c|c|}
\hline Date & Sensor & Country & Src IP & Dst port & Protocol & Honeypot \\
\hline $2020-06-27$ 11:47:01 & dionaea & $?$ & 192.168.1.35 & 80 & httpd & dionaea \\
\hline
\end{tabular}

Gambar 13 Serangan DoS pada Dionaea

Sebaliknya dengan Honeypot Cowrie menangkap sedikit serangan yang telah dikirmkan. Bahkan pada suatu hari Cowrie hanya menangkap satu serangan sedangkan serangan yang dikirmkan ada tiga

\begin{tabular}{|c|c|c|c|c|c|c|c|}
\hline & Date & Sensor & Country & Src IP & Dst port & Protocol & Honeypot \\
\hline 1 & $2020-06-27$ 11:39:35 & cowrie-panda & 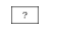 & 192.168.1.35 & 22 & ssh & cowrie \\
\hline 2 & $2020-06-27$ 11:31:05 & cowrie-panda & 7 & 192.168.1.35 & 22 & ssh & cowrie \\
\hline 3 & 2020-06-27 06:43:19 & cowrie-panda & 7 & 192.168.1.35 & 22 & ssh & cowrie \\
\hline 4 & 2020-06-27 06:43:19 & cowrie-panda & 7 & 192.168.1.35 & 22 & ssh & cowrie \\
\hline 5 & 2020-06-27 06:43:19 & cowrie-panda & 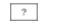 & 192.168 .1 .35 & 22 & ssh & cowrie \\
\hline 6 & 2020-06-27 06:43:19 & cowrie-panda & 7 & 192.168.1.35 & 22 & ssh & cowrie \\
\hline 7 & 2020-06-27 06:43:19 & cowrie-panda & 7 & 192.168.1.35 & 22 & ssh & cowrie \\
\hline 8 & 2020-06-27 06:43:19 & cowrie-panda & 7 & 192.168.1.35 & 22 & ssh & cowrie \\
\hline 9 & 2020-06-27 06:43:19 & cowrie-panda & 7 & 192.168 .1 .35 & 22 & ssh & cowrie \\
\hline 10 & 2020-06-27 06:43:19 & cowrie-panda & $?$ & 192.168.1.35 & 22 & ssh & cowrie \\
\hline
\end{tabular}

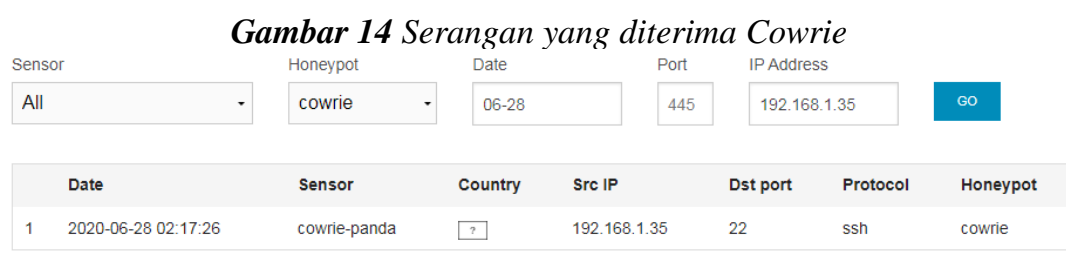

Gambar 15 Serangan yang diterima hanya satu

\subsection{Import log dari MHN menuju MySQL}

Sebelum melakukan visualisasi di grafana, data dari MHN akan di import terlebih dahulu menuju MySQL. Disini peneliti membuat sebuah program dengan bahasa Python yang berfungsi mengambil data dari database MHN dan mengirimnya menuju database MySQL. Program memiliki dua method yang pertama berfungsi mengambil data dari MongoDB dan menyimpannya dalam variable dan yang kedua berfungsi untuk membaca variable tersebut dan memasukkannya ke dalam MySQL. Berikut adalah screenshot yang digunakan 


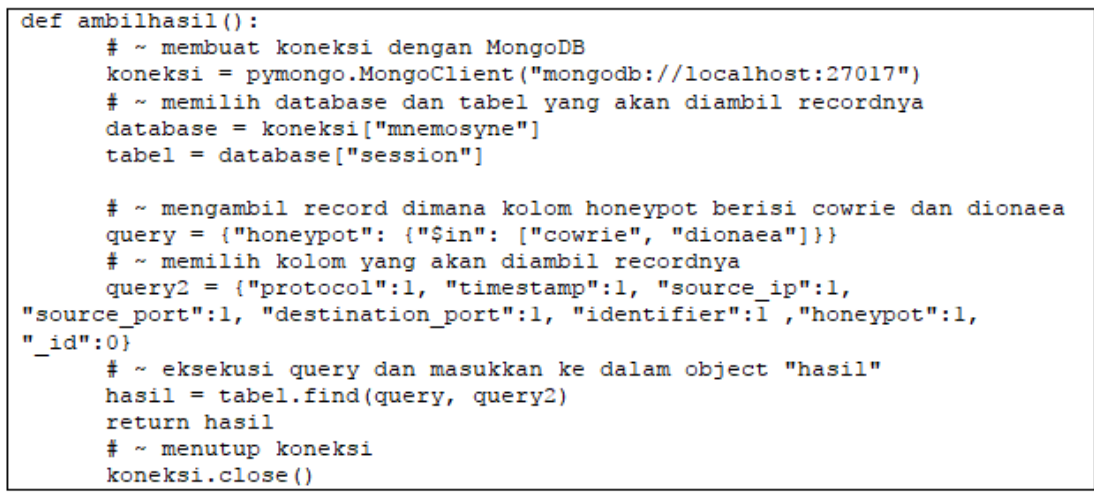

Gambar 16 method pertama pada program

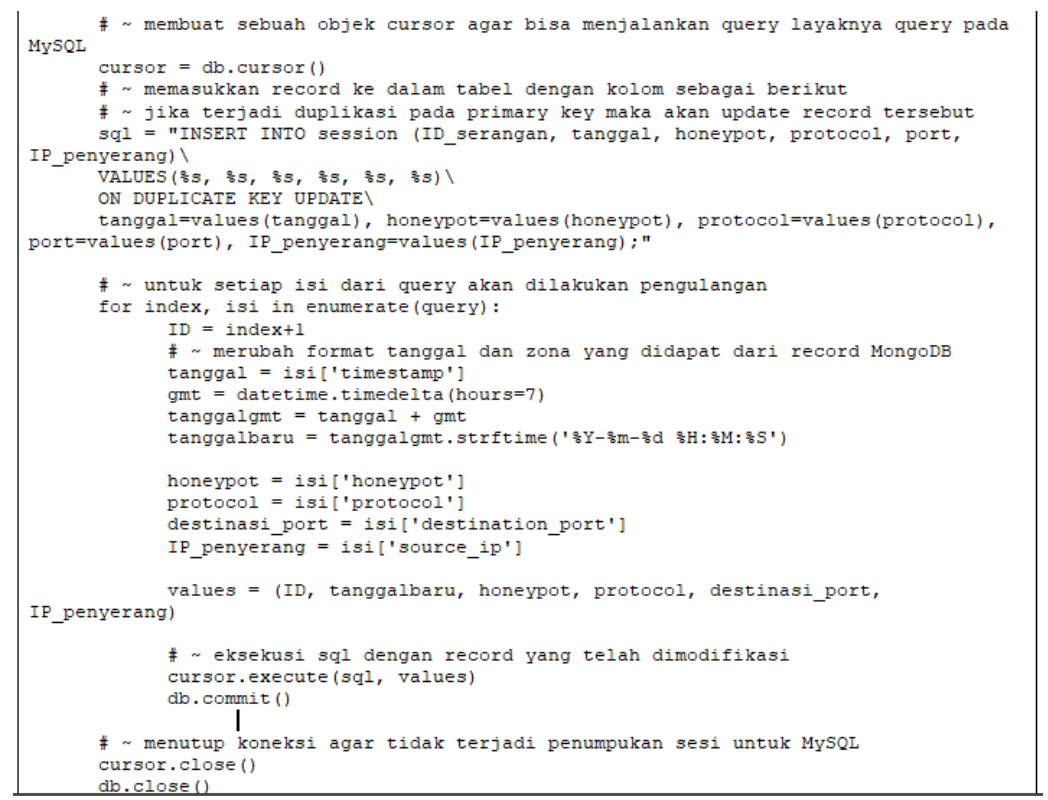

Gambar 17 method kedua pada program

Hasil dari program tersebut dapat dilihat pada database MySQL

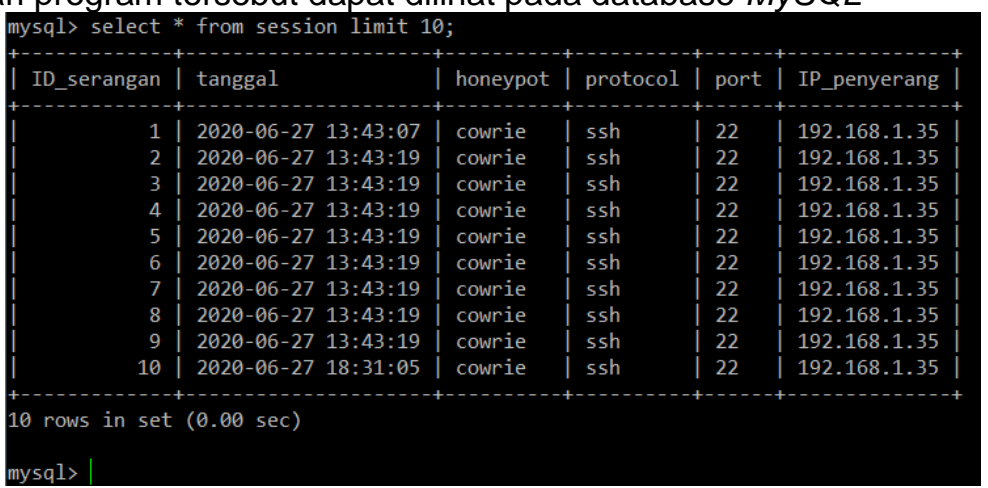

Gambar 18 Record hasil import dari MongoDB

\subsection{Visualisasi menggunakan Grafana}

Tahap terakhir dari pengujian ini adalah memvisualisasikan data pada MySQL dengan Grafana. Grafana harus dihubungkan dengan sumber data terlebih dahulu, yakni database MySQL untuk mengambil data yang akan divisualisasikan. Setelah Grafana terhubung dengan MySQL berikutnya ialah membuat dashboard dan panel. Dashboard merupakan tempat diperlihatkannya 
panel - panel, sedangkan panel adalah tempat untuk memvisualkan data yang diambil dari sumberdata. Panel menggunakan Query yang sama dengan sumber data untuk mengambil data. Pada panel terdapat Query Editor yang dapat membantu pengguna untuk menuliskan Query agar tampil pada panel. Pengguna dapat juga menuliskan Query sendiri tanpamenggunakan Query Editor. Berikut adalah hasil dari visualisasi dengan menggunakan Grafana

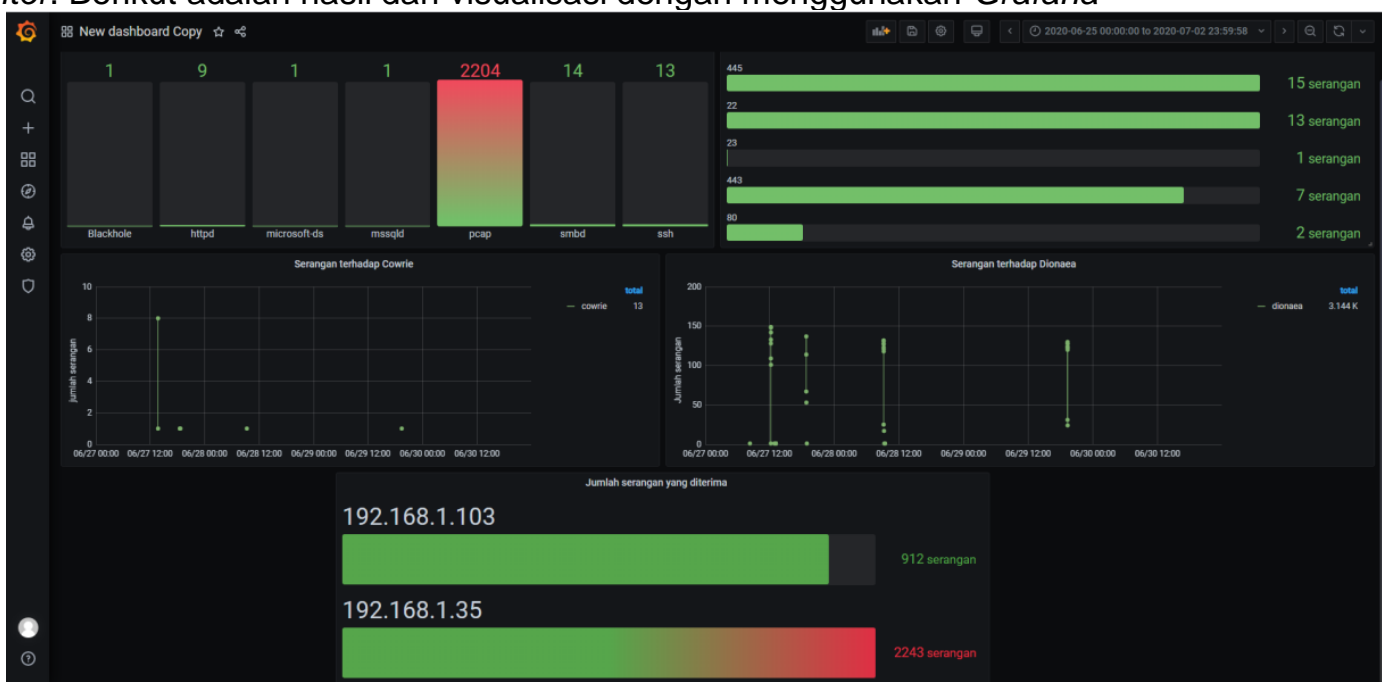

Gambar 19 Hasil Visualisasi menggunakan Grafana

pada Gambar 20 terlihat Grafana menampilkan berbagai macam data seperti serangan terhadap honeypot, IP penyerang, port yang diserang serta protocol yang berjalan

\section{Kesimpulan dan Saran}

\subsection{Kesimpulan}

Berdasarkan dari hasil pengmplementasian dan pengujian sistem yang dibangun pada penelitian "Modern Honey Network dengan Grafan untuk Visualisasi" dapat ditarik kesimpulan antara lain

1. Dibutuhkan database lain untuk mengintegrasikan Modern Honey Network dengan Grafana dikarenakan Grafana tidak mendukung MongoDB sebagai sumber data

2. Grafana mampu mevisualisasikan data yang diberikan ke dalam bentuk grafik sesuai dengan keinginan peneliti

\subsection{Saran}

Berdasarkan dari hasil penelitian ini masih terdapat kekurangan sehingga memungkinkan digunakan sebagai acuan untuk pengemabangan penelitian selanjutnya

1. Dapat mengintegrasikan Modern Honey Network dan Grafana secara langsung tanpa menggunakan Database lain seperti MySQL atau Prometheus

2. Menambahkan jumlah Honeypot dan Sensor yang digunakan dalam penelitian untuk mendapatkan hasil yang lebih beragam.

3. Pemasangan Honeypot dan Sensor pada jaringan yang berbeda tetapi tetap bisa berkomunikasi dengan Modern Honey Network.

\section{Refrensi}

[1] U. Gasser, J. Zittrain, R. Faris, and R. H. Jones, "Internet Monitor 2014: Reflections on the Digital World: Platforms, Policy, Privacy, and Public Discourse," vol. 2014-17, p. 155, 2014.

[2] B. B. Gupta, D. P. Agrawal, and H. Wang, Computer and Cyber Security: Principles, Algorithm, Applications, and Perspectives, no. 9. Boca Raton: CRC Press, 2019.

[3] LanceSpitzner, Honeypots: Tracking Hackers, 2nd ed. Addison Wesley, 2002.

[4] P. Kenealy and W. J. Noonan, Virtualization for Security, 1st ed. Burlington: Syngress Publishing, Inc., 2009.

[5] S. M. Jigneshkumar, "Modern Honey Network," Int. J. Res. Advent Technol., no. Special Issue, pp. 156-162, 2016.

REPOSITOR, Vol. 2, No. 10, Oktober 2020, Pp. 1380-1389 
[6] M. Mohammed and H. Rehman, Honeypots and Routers, Collecting Internet Attacks. Boca Raton: CRC Press, 2016.

[7] H. Wafi, A. Fiade, N. Hakiem, and R. B. Bahaweres, "Implementation of a Modern Security Systems Honeypot Honey Network on Wireless Networks," Int. Young Eng. Forum, pp. 91-96, 2017.

[8] "What is Grafana? I Grafana Labs." [Online]. Available: https://grafana.com/docs/grafana/latest/guides/what-is-grafana/. [Accessed: 04-Apr2020].

[9] V. Bontchev and V. Yosifova, "Analysis of the Global Attack Landscape Using Data from a Telnet Honeypot," vol. 43, no. 2, pp. 264-282, 2019.

[10] R. S. Pressman, Book review: Software Engineering: a Practitioner's Approach, 5th ed., vol. 10, no. 6. Thomas Cason, 1995. 